\title{
On the Role of Voltage-Dependent Calcium Channels in Calcium Signaling of Astrocytes In Situ
}

\author{
Giorgio Carmignoto, Lucia Pasti, and Tullio Pozzan \\ Department of Experimental Biomedical Sciences and Consiglio Nazionale delle Ricerche Center for the Study of \\ Biomembranes, University of Padova, 35121 Padova, Italy
}

\begin{abstract}
Calcium ions play crucial roles in a large variety of cell functions. The recent proposal that changes in the intracellular calcium concentration $\left(\left[\mathrm{Ca}^{2+}\right]_{\mathrm{i}}\right)$ in astrocytes underline a reciprocal communication system between neurons and astrocytes encourages the interest in the definition of the various components participating in this novel $\mathrm{Ca}^{2+}$ signaling system. We investigate here whether functional voltage-operated calcium channels ( $\mathrm{Ca}^{2+}$ VOCs), which are clearly expressed in cultured astrocytes, participate in the regulation of $\left[\mathrm{Ca}^{2+}\right]_{i}$ also in astrocytes in situ. Depolarization with $40-60 \mathrm{~mm} \mathrm{~K}^{+}$was used to analyze the activity of $\mathrm{Ca}^{2+}$ VOCs in Indo-1-loaded astrocytes in acute slices from the visual cortex and the CA1 hippocampal region of developing rats. We demonstrate here that the depolarization-induced $\left[\mathrm{Ca}^{2+}\right]_{i}$ increases in astrocytes are solely attributed to the activation of metabotropic receptors by neurotransmitters, such as glutamate, released by synaptic
\end{abstract}

terminals on depolarization. In fact, (1) the $\mathrm{K}^{+}$-induced $\left[\mathrm{Ca}^{2+}\right]_{\mathrm{i}}$ increases in astrocyte $\left[\mathrm{Ca}^{2+}\right]_{\mathrm{i}}$ were potently reduced by $\alpha$-methyl-4-carboxyphenylglycine, a metabotropic glutamate receptor competitive inhibitor; (2) after emptying intracellular $\mathrm{Ca}^{2+}$ stores with cyclopiazonic acid, none of the astrocytes displayed a $\left[\mathrm{Ca}^{2+}\right]_{i}$ increase on the depolarizing stimulus; and (3) after inhibiting neurotransmitter secretion in neurons by incubating the slices with tetanus neurotoxin, no $\left[\mathrm{Ca}^{2+}\right]_{i}$ increase on $\mathrm{K}^{+}$stimulation was observed in astrocytes. Finally, patch-clamp whole-cell recordings from hippocampal astrocytes in acute brain slices failed to reveal any voltagedependent calcium currents. On the basis of these results, the various roles proposed for astrocyte $\mathrm{Ca}^{2+}$ VOCs in the CNS should be reconsidered.

Key words: calcium channels; glutamate; astrocyte-neuron interactions; confocal microscope; patch-clamp; brain slices; rat
Numerous stimuli such as neurotransmitters, membrane depolarization, or mechanical stress elicit in astrocytes increases in the concentration of intracellular calcium $\left(\left[\mathrm{Ca}^{2+}\right]_{i}\right)$ that are quite variable in terms of amplitude and spatiotemporal organization: $\left[\mathrm{Ca}^{2+}\right]_{i}$ peaks and prolonged plateaus and oscillations (CornellBell et al., 1990; Glaum et al., 1990; Jensen and Chiu, 1991; Pasti et al., 1995), often followed by propagating $\left[\mathrm{Ca}^{2+}\right]_{\mathrm{i}}$ waves (Cornell-Bell et al., 1990; Charles et al., 1991). This complexity reflects the expression of a variety of molecules that control $\mathrm{Ca}^{2+}$ entry from the extracellular space as well as $\mathrm{Ca}^{2+}$ release from intracellular compartments (Berridge, 1993; Verkhratsky and Kettenmann, 1996). In particular, cultured astrocytes from different brain regions express a variety of ion channels, including both T- and L-type $\mathrm{Ca}^{2+}$ channels. The first evidence for $\mathrm{Ca}^{2+}$ channel activity in cultured astrocytes was obtained by the discovery of $\mathrm{Ca}^{2+}$-dependent action potential firing on intracellular current injections (MacVicar, 1984). The presence of voltageoperated $\mathrm{Ca}^{2+}$ channels $\left(\mathrm{Ca}^{2+}\right.$ VOCs) was then demonstrated by recording L-type $\mathrm{Ca}^{2+}$ current sensitive to nifedipine (MacVicar and Tse, 1988). The expression of $\mathrm{Ca}^{2+}$ channels in

Received March 6, 1998; accepted April 8, 1998.

This manuscript was supported by Telethon Grant 845, European Union Programs, Human Capital and Mobility Network Grant CHRXCT940500, Human Frontier Science Program Grant RG520/95, Italian University Ministry, Fidia Research Laboratories, and Biotechnology Program Grant 0BIO4CT960382. We thank Aldebaran Hofer and Daniela Pietrobon for helpful discussion and critical reading of this manuscript and Cesare Montecucco for the generous gift of the purified tetanus toxin.

Correspondence should be addressed to Giorgio Carmignoto, Department of Experimental Biomedical Sciences, University of Padova, Viale G. Colombo 3, 35131 Padova, Italy.

Copyright $\odot 1998$ Society for Neuroscience $0270-6474 / 98 / 184637-09 \$ 05.00 / 0$ cultured astrocytes appears to depend either on the presence of neurons (Corvalan et al., 1990) or on treatments with agents that increased cAMP intracellular levels (MacVicar and Tse, 1988; Barres et al., 1989). Using classical $\mathrm{Ca}^{2+}$ imaging techniques, $\left[\mathrm{Ca}^{2+}\right]_{\mathrm{i}}$ elevations attributed to $\mathrm{Ca}^{2+}$ influx through $\mathrm{Ca}^{2+}$ VOCs were observed in astrocytes on a depolarizing stimulus (Jensen and Chiu, 1991; MacVicar et al., 1991). Although the evidence for the expression of $\mathrm{Ca}^{2+}$ VOCs in cultured astrocytes is beyond any doubt, results obtained in culture do not necessarily represent faithfully the behavior of astrocytes in vivo. To address this criticism, several authors have studied this problem under conditions that more closely resemble the in vivo situation. Astrocytes acutely isolated from the optic nerve displayed $\mathrm{Ca}^{2+}$ currents typical of $\mathrm{T}$ - and L-type $\mathrm{Ca}^{2+}$ channel activity (Barres et al., 1990). Several authors also demonstrated that acutely dissociated astrocytes from the hippocampus (Duffy and MacVicar, 1994) as well as astrocytes from acute brain slices (Porter and McCarthy, 1995; Duffy and MacVicar, 1996), increased their $\left[\mathrm{Ca}^{2+}\right]_{\mathrm{i}}$ on $\mathrm{K}^{+}$ stimulation. This response was either inhibited (Duffy and MacVicar, 1996) or significantly reduced (Porter and McCarthy, 1995 ) by the $\mathrm{Ca}^{2+}$ channel antagonist verapamil.

Studies with sharp microelectrodes or patch-clamp techniques from astrocytes either acutely isolated or from brain slices failed, however, to reveal voltage-dependent $\mathrm{Ca}^{2+}$ currents (Duffy and MacVicar, 1994; Jabs et al., 1994; Kressin et al., 1995; Steinhäuser et al., 1994). These negative results have been interpreted as being attributable to an inadequate control of membrane potential, because these cells extensively communicate through gap junctions, thereby forming an electrotonically coupled network. The visualization of $\left[\mathrm{Ca}^{2+}\right]_{i}$ changes on a depolarizing stimulus 
and their inhibition by pharmacological tools remain the only results supporting an active role of $\mathrm{Ca}^{2+}$ VOCs in $\mathrm{Ca}^{2+}$ signaling of astrocytes in situ and, implicitly, the presence of $\mathrm{Ca}^{2+}$ VOCs in these cells. The expression of VOCs in astrocytes represents, therefore, an open question. Noteworthy, subpopulations of astrocytes probably exist in the CNS (McKhann et al., 1997). For example, a recent study performed in acute brain slices demonstrated the presence of $\mathrm{Ca}^{2+}$ currents in the so-called "complex" cells from the mouse hippocampus (Akopian et al., 1996). These cells were neither GFAP-positive nor dye-coupled and were therefore proposed to represent a distinct type of hippocampal glial cells, perhaps immature astrocytes (Kressin et al., 1994; Akopian et al., 1996). Given the potential importance of these channels in astrocyte function under physiological as well as pathological conditions, we addressed this problem in detail. A confocal fluorescence microscope and the $\mathrm{Ca}^{2+}$ indicator Indo- 1 were used to follow the $\left[\mathrm{Ca}^{2+}\right]_{\mathrm{i}}$ changes in neurons and astrocytes from both hippocampal and cortical slices. In addition, the patch-clamp technique was applied to record possible voltageactivated calcium currents from astrocytes in situ as well as from astrocytes after detaching their cell body off from the slice by gentle withdrawal of the patch pipette. Our results indicate that the $\left[\mathrm{Ca}^{2+}\right]_{\mathrm{i}}$ increase observed in astrocytes in response to a depolarizing stimulus with high $\mathrm{K}^{+}$is not caused by $\mathrm{Ca}^{2+}$ entry through VOCs but rather to $\mathrm{Ca}^{2+}$ release from intracellular $\mathrm{Ca}^{2+}$ stores after activation of G-protein-linked receptors by glutamate and possibly other neurotransmitters released from depolarized synaptic terminals.

\section{MATERIALS AND METHODS}

Slice preparation and dye loading. Transverse brain slices $(150-250 \mu \mathrm{m})$ from both the visual cortex and the hippocampus were prepared from Wistar rats at postnatal days 5-18 (P5-P18) as described previously (Carmignoto and Vicini, 1992). After evidence that antioxidant agents can protect neurons from degeneration (Rice et al., 1994), the physiological saline for slice cutting was as follows (in $\mathrm{mM}$ ): $120 \mathrm{NaCl}, 3.1 \mathrm{KCl}$, $1.25 \mathrm{NaH}_{2} \mathrm{PO}_{4}, 25 \mathrm{NaHCO}_{3}, 4$ dextrose, $2 \mathrm{MgCl}_{2}, 1 \mathrm{CaCl}_{2}, 2 \mathrm{Na}-$ pyruvate, 0.5 myoinositol, and 0.1 ascorbic acid, $\mathrm{pH} 7.4$, with $5 \% \mathrm{CO}_{2}$ and $95 \% \mathrm{O}_{2}$. After cutting, slices were allowed to recover for $10-15 \mathrm{~min}$ at $37^{\circ} \mathrm{C}$ in the physiological saline used for cutting. Dye loading was performed in the same physiological saline used for cutting supplemented with the cell-permeant Indo-1 AM $(20 \mu \mathrm{M}$; Molecular Probes, Eugene, OR) and $0.02 \%$ pluronic acid at $37^{\circ} \mathrm{C}$ for $40-50$ min under continuous influx of the gas mixture $\left(5 \% \mathrm{CO}_{2}\right.$ and $\left.95 \% \mathrm{O}_{2}\right)$. In several experiments, tetanus neurotoxin (TeNT, $100 \mu \mathrm{g} / \mathrm{ml}$ ) was added for the entire time of the Indo-1 loading. Continuous mild stirring was found to be crucial for optimizing the loading of the dye. After this procedure, the loading of neurons was as good as that of astrocytes.

Image acquisition. After incubation with Indo-1 AM, slices were mounted in a chamber that was placed on the stage of a Nikon Diaphot 300 inverted microscope, equipped with a $40 \times$ water immersion objective (numerical aperture, 1.1) (Nikon) connected to a real-time confocal microscope (Nikon RCM8000). The $351 \mathrm{~nm}$ band of the argon ion laser was used for excitation, and the emitted light, separated into its two components ( 405 and $485 \mathrm{~nm}$ ) by a dichroic mirror was collected by two separate photomultipliers. The ratio of the intensity of the light emitted at the two wavelengths ( 405 and $485 \mathrm{~nm}$ ) was displayed as a pseudocolor scale. Images were acquired with a frame interval of 2 or $30 \mathrm{sec}$, and 16 images were averaged for each frame. Recording sessions were performed at room temperature $\left(20-23^{\circ} \mathrm{C}\right)$. Slices were continuously perfused $(3 \mathrm{ml} / \mathrm{min})$ with physiological saline of the following composition (in mM): $120 \mathrm{NaCl}, 3.1 \mathrm{KCl}, 1.25 \mathrm{NaH}_{2} \mathrm{PO}_{4}, 25 \mathrm{NaHCO}_{3}, 5$ dextrose, 1 $\mathrm{MgCl}_{2}$, and $2 \mathrm{CaCl}_{2}, \mathrm{pH} 7.4$, with $5 \% \mathrm{CO}_{2}$ and $95 \% \mathrm{O}_{2}$. The $405: 485 \mathrm{~nm}$ emission ratio ( $\mathrm{R} 405: 485)$ in basal conditions was observed to vary little in different cells. Occasionally, a slight decrease was observed in R405: 485 basal levels. Indeed, prolonged UV irradiation of Indo-1 can cause overall photobleaching and conversion to a fluorescent, but $\mathrm{Ca}^{2+}$ insensitive, species (Scheenen et al., 1996). In several experiments, we used $100 \mu \mathrm{M}$ Trolox, a vitamin E analog that inhibits formation of Indo-1 photodegradation products (Scheenen et al., 1996). No substantial differences were, however, observed in our conditions. The stimulation with high- $\mathrm{K}^{+}$extracellular solution was obtained by isosmotic replacement of $\mathrm{Na}^{+}$with $\mathrm{K}^{+}$.

Electrophysiological recordings. Standard procedures were used for pipette preparation and patch-clamp recording in the whole-cell configuration (Edwards et al., 1989; Carmignoto and Vicini, 1992). Acute hippocampal slices were continuously perfused (3-5 $\mathrm{ml} / \mathrm{min}$ ) with a bath solution of the following composition (in $\mathrm{mM}$ ): $140 \mathrm{NaCl}, 3 \mathrm{KCl}, 1$ $\mathrm{MgCl}_{2}, 2 \mathrm{CaCl}_{2}, 10$ glucose, and $10 \mathrm{HEPES}$, to $\mathrm{pH} 7.4$ with $\mathrm{KOH}$. The solutions were continuously bubbled with $5 \% \mathrm{CO}_{2}$ and $95 \% \mathrm{O}_{2}$. Cells were viewed with an upright Zeiss Axioskop microscope equipped with differential interference contrast, Nomarski optics (UEM; Zeiss, Oberkochen, Germany), and an electrically insulated water immersion $40 \times$ objective with a long working distance $(2 \mathrm{~mm})$. For the investigation of calcium currents, we used an extracellular solution of the following composition (in $\mathrm{mM}$ ): 135 tetraethylammonium chloride (TEA), 10 $\mathrm{BaCl}_{2}, 5$ glucose, and 10 HEPES, to $\mathrm{pH} 7.4$ with tetraethyammonium hydroxide (TEAOH). With respect to $\mathrm{Ca}^{2+}, \mathrm{Ba}^{2+}$ slows the rate of channel inactivation and is more permeant than $\mathrm{Ca}^{2+}$ through most of $\mathrm{Ca}^{2+}$ channels, thus producing larger currents. The pipette solution contained (in mM): $60 \mathrm{~N}$-methyl-D-glucamine (NMDG)-Cl, $60 \mathrm{CsCl}, 2$ $\mathrm{MgCl}_{2}$, 20 TEA, 5 EGTA, 3.0 $\mathrm{Na}_{2}$-ATP, $0.2 \mathrm{Na}_{2}$-GTP, and 10 HEPES, to $\mathrm{pH} 7.2$ with TEAOH. In a number of experiments, $120 \mathrm{~mm}$ Csmethanesulfonate replaced $\mathrm{NMDGCl}$ and $\mathrm{CsCl}$. Lucifer yellow (LY; $0.1 \%$ ) was included in the patch pipette. Recordings were performed in current and voltage clamp with a patch-clamp amplifier (EPC 7; List Electronics, Darmstadt, Germany), sampled at 5 or $10 \mathrm{kHz}$, filtered at 1.5 $\mathrm{kHz}$ (eight-pole low-pass Bessel filter; Frequency Devices, Haverhill, MA), and digitized by a Digidata 1200A interface. pCLAMP-6 software (Axon Instruments) was used for acquisition and analysis of data. Linear capacity and leakage currents were measured and subtracted during acquisition except in the experiments in which subtraction of the current traces recorded before and after slice perfusion with $100 \mu \mathrm{M} \mathrm{Cd}^{2+}$ was applied off-line. Series resistance compensation (20-40\%) was used to ameliorate the voltage-clamp control. To reduce access resistance, pipette resistance was normally $<4 \mathrm{M} \Omega$. In several experiments, after establishing the whole-cell configuration, astrocytes were detached from the slice by carefully withdrawing the patch pipette and applying a mild suction through the pipette. The possible presence of $\mathrm{Ca}^{2+}$ currents in three detached astrocytes was investigated.

Drugs. The excitatory amino acid receptor agents NMDA, $\alpha$-methyl4-carboxyphenylglycine (MCPG), 2-amino-5-phosphonopentanoic acid (D-AP-5), and 1-aminocyclo-pentane-1,3-dicarboxylic acid ( $t$-ACPD) were from Tocris (Buckhurst Hill, UK); cyclopiazonic acid (CPA), tetrodotoxin (TTX), Trolox, lucifer yellow (dilithium salt), and verapamil were from Sigma (Milan, Italy). These compounds were dissolved in water, $\mathrm{NaOH}$, or dimethylsulfoxide and diluted in the physiological saline used for recordings. Purified TeNT (Schiavo and Montecucco, 1995) was a gift from C. Montecucco, Department of Experimental Biomedical Sciences, University of Padova.

\section{RESULTS}

\section{High- $\mathrm{K}^{+}$-induced $\left[\mathrm{Ca}^{2+}\right]_{\mathrm{i}}$ increase in astrocytes}

In a series of previous experiments aimed at clarifying the role of $\left[\mathrm{Ca}^{2+}\right]_{\mathrm{i}}$ oscillations in astrocytes from acute brain slices, we observed that, although the application of a depolarizing stimulus such as $40-60 \mathrm{mM} \mathrm{KCl}$ resulted in a rise of the $\left[\mathrm{Ca}^{2+}\right]_{i}$ in astrocytes, this increase was delayed several seconds with respect to that in neurons. We described previously the experimental approach that allows us to identify astrocytes and neurons in situ on the basis of their morphological, electrophysiological, immunocytological, and pharmacological criteria (Pasti et al., 1997) and demonstrated that the different kinetics of the response to $\mathrm{K}^{+}$stimulation is a characteristic feature of the astrocyte and can thus be used as a diagnostic tool to distinguish neurons and astrocytes in situ. The sequence of pseudocolor images of Figure $1 A$ illustrates the typical behavior of the $\left[\mathrm{Ca}^{2+}\right]_{\mathrm{i}}$ change in neurons and astrocytes from the hippocampal CA1 region on perfusion with $40 \mathrm{~mm} \mathrm{KCl}$, as revealed by the fluorescent indicator Indo-1. Whereas pyramidal neurons, cells marked with 


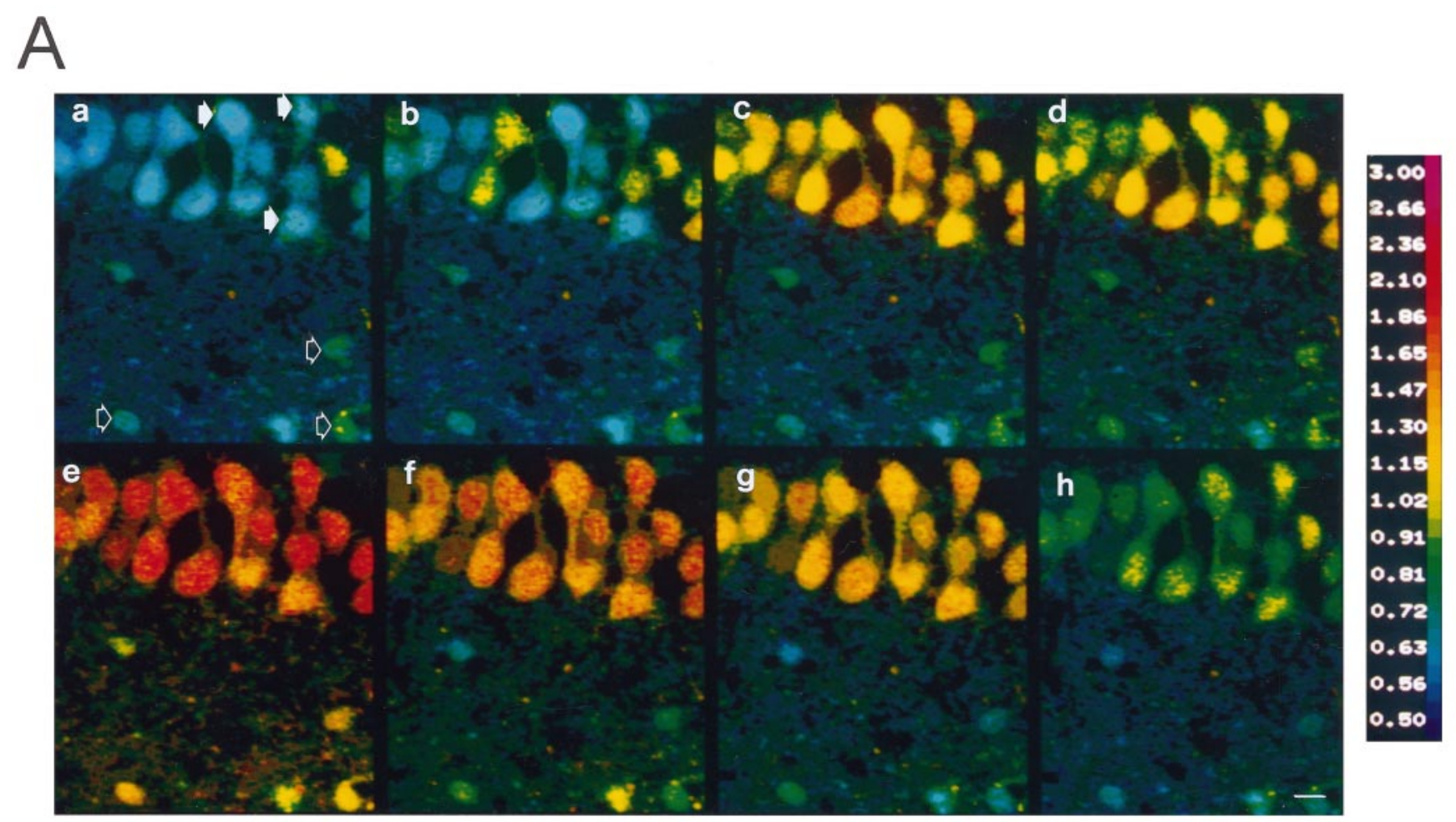

R 405/485
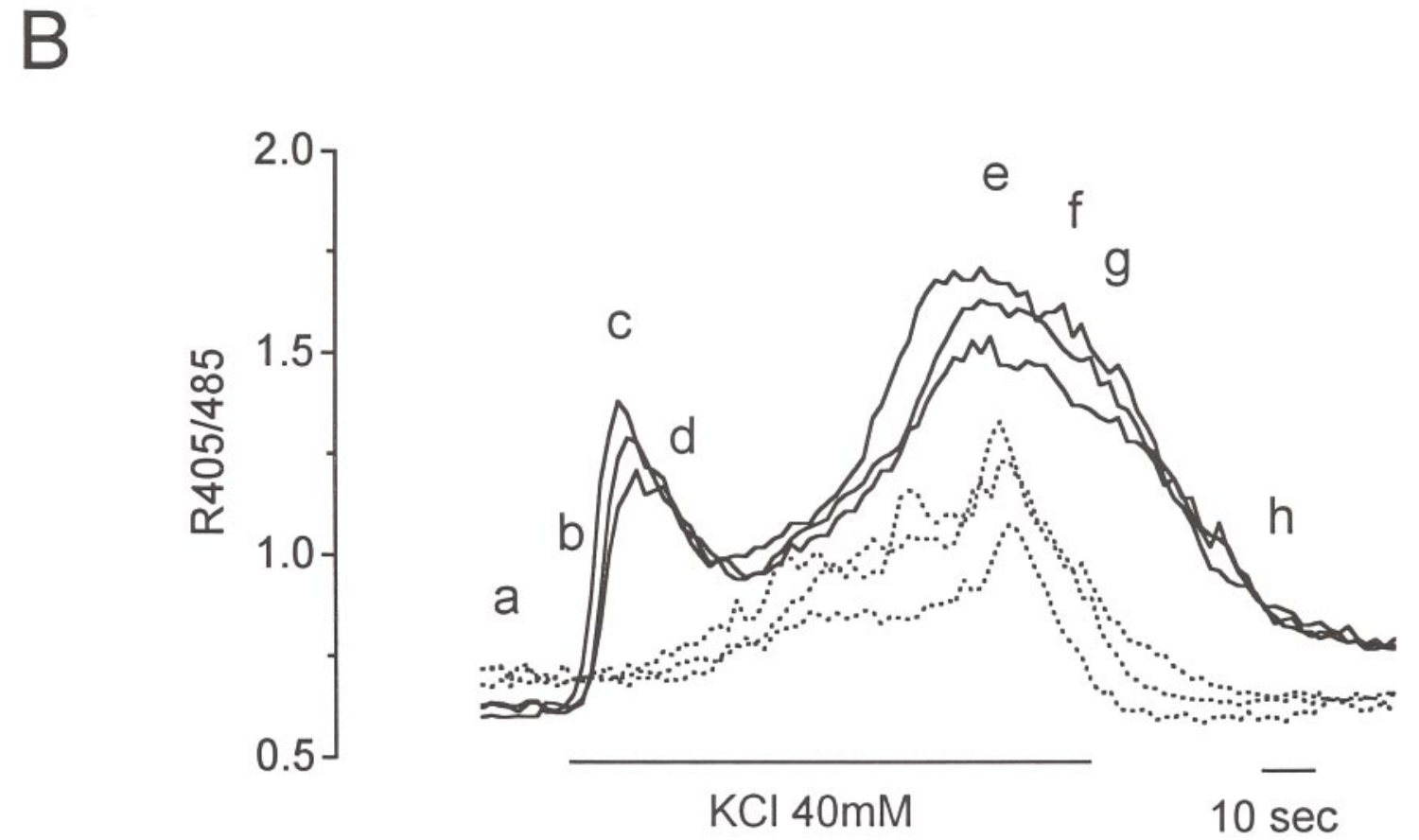

Figure 1. Response in neurons and astrocytes to stimulation with $40 \mathrm{mM} \mathrm{KCl}$. $A$, Time series of pseudocolor images of the $\left[\mathrm{Ca}{ }^{2+}\right]_{\mathrm{i}}$ changes occurring in

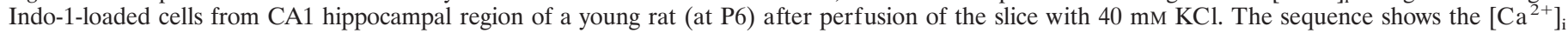
increase in pyramidal neurons (closed arrows) occurring several seconds before that in astrocytes (open arrows). The R405:485 is displayed as a pseudocolor scale. Sampling rate, $2 \mathrm{sec}$; scale bar, $10 \mu \mathrm{m} . B$, Kinetics of the $\left[\mathrm{Ca}^{2+}\right]_{\mathrm{i}}$ changes in the neurons (continuous lines) and the astrocytes (dotted lines), indicated by the arrows in $A$, after $\mathrm{K}^{+}$stimulation, as expressed by the ratio between Indo-1 emission wavelength at 405 and $485 \mathrm{~nm}$. $a-h$, Images $a-h$ in $A$.

closed arrowheads in Figure $1 \mathrm{Aa}$, displayed a prompt $\left[\mathrm{Ca}^{2+}\right]_{\mathrm{i}}$ increase on depolarization with high extracellular $\mathrm{K}^{+}$, astrocytes, cells marked with open arrowheads, initially failed to respond but displayed a significant $\left[\mathrm{Ca}^{2+}\right]_{\mathrm{i}}$ increase several seconds after that of pyramidal neurons (Fig. 1A). In two experiments, cells were followed for at least $10 \mathrm{~min}$, but no further delayed responses were observed in astrocytes. The same pattern of responses was observed in electrophysiologically classified astrocytes and neu- 


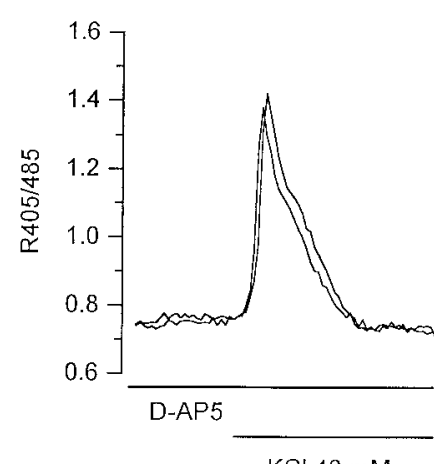

$\mathrm{KCl} 40 \mathrm{mM}$

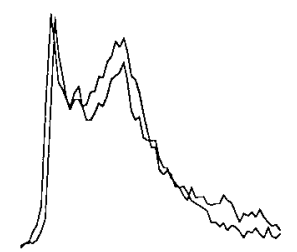

$\overline{30 \mathrm{sec}}$

$\mathrm{KCl} 40 \mathrm{mM}$

Figure 2. Kinetics of the $\left[\mathrm{Ca}^{2+}\right]_{\mathrm{i}}$ change in two representative hippocampal pyramidal neurons to $\mathrm{K}^{+}$stimulation in the presence of the NMDAR antagonist D-AP-5 (left) and $15 \mathrm{~min}$ after the onset of its washout (right).

rons loaded with Indo-1 through the patch pipette (Pasti et al., 1997). Given that the kinetics of the astrocyte $\left[\mathrm{Ca}^{2+}\right]_{\mathrm{i}}$ increase on high $\mathrm{K}^{+}$stimulation (Fig. $1 B$ ) is hardly compatible with a participation of $\mathrm{Ca}^{2+}$ VOCs, what might be a plausible explanation for this delayed response? We hypothesized that it could be, to a large extent, attributable to the release of glutamate and/or other neurotransmitters by depolarized synaptic terminals and to the subsequent activation of metabotropic receptors linked to inositol trisphosphate $\left(\mathrm{IP}_{3}\right)$ production. This event may also account for the biphasic response in neurons (Fig. $1 A, B$ ). Noteworthy, the pattern of $\left[\mathrm{Ca}^{2+}\right]_{\mathrm{i}}$ changes in neurons and astrocytes on high $\mathrm{K}^{+}$ stimulation described above was observed to be qualitatively similar in slices from rats at P5, P7, P12, and P18.

A first result that gave support to the above-mentioned hypothesis was obtained by investigating the origin of the biphasic response in neurons. The second $\left[\mathrm{Ca}^{2+}\right]_{i}$ peak that usually occurred in neurons at approximately the same time of the $\left[\mathrm{Ca}^{2+}\right]_{\mathrm{i}}$ increase in astrocytes was found to be caused by the activation of NMDA receptors. It was, in fact, abolished by the application of the NMDA receptor antagonist D-AP-5 (Watkins et al., 1990) (Fig. 2, left) and recovered after the second high $\mathrm{K}^{+}$challenge performed $10 \mathrm{~min}$ after the washout of the antagonist (Fig. 2, right). In contrast, the response from astrocytes was unchanged (data not shown). Similar results were obtained in neurons and astrocytes from the visual cortex.

We previously obtained evidence (Pasti et al., 1997) that the application of $1 \mathrm{~mm} \mathrm{MCPG,} \mathrm{a} \mathrm{metabotropic} \mathrm{glutamate} \mathrm{receptor}$ (mGluR) competitive inhibitor (Watkins and Collingridge, 1994), drastically reduced the $\left[\mathrm{Ca}^{2+}\right]_{\mathrm{i}}$ increase triggered in astrocytes by synaptically released glutamate as well as that induced by the specific mGluR agonist $t$-ACPD (10 $\mu \mathrm{M}$; Palmer et al., 1989). We have found that the $\left[\mathrm{Ca}^{2+}\right]_{\mathrm{i}}$ increase induced by $\mathrm{K}^{+}$stimulation in the presence of $1 \mathrm{mM}$ MCPG was reduced to $60.5 \pm 3.14 \%$ (mean $\pm \mathrm{SE} ; n=7$; two experiments) with respect to controls.

The delay in the astrocyte response with respect to the response in neurons on a first high $\mathrm{K}^{+}$challenge was significantly increased $(t$ test, $p<0.01)$ after a second high $\mathrm{K}^{+}$stimulation $(12.4 \pm 0.6$ vs $15.6 \pm 1.1 \mathrm{sec}$; mean $\pm \mathrm{SE} ; n=23)$ performed 10 min after slice perfusion with $10 \mu \mathrm{M}$ TTX. The amplitude of the response was unchanged. The occurrence of the second $\left[\mathrm{Ca}^{2+}\right]_{i}$ peak in the response of neurons displayed a parallel delay, whereas the amplitude was unchanged. These results suggest that the entry of $\mathrm{Na}^{+}$through voltage-dependent $\mathrm{Na}^{+}$channels is involved in the release of glutamate triggered by high $\mathrm{K}^{+}$stim-

ulation most likely by affecting the kinetics of the depolarization in neurons.

\section{$\mathrm{Ca}^{2+}$ VOCs do not contribute to the $\mathrm{K}^{+}$-induced $\left[\mathrm{Ca}^{2+}\right]_{\mathrm{i}}$ increase in astrocytes}

Altogether, although the results from the experiments described above cannot allow definitive conclusions on the possible expression of functional $\mathrm{Ca}^{2+}$ VOCs in astrocytes, they cast important doubts as to the interpretation of some previous data. The role of $\mathrm{Ca}^{2+}$ VOCs in the $\left[\mathrm{Ca}^{2+}\right]_{\mathrm{i}}$ increase induced in astrocytes by $\mathrm{K}^{+}$ stimulation was, therefore, subjected to more stringent experiments, whose results are reported in Figures 3 and 4. If the activation of mGluRs by glutamate fully accounts for the $\left[\mathrm{Ca}^{2+}\right]_{\mathrm{i}}$ increase triggered in astrocytes by $\mathrm{K}^{+}$stimulation, one would predict that (1) depletion of intracellular $\mathrm{Ca}^{2+}$ stores should inhibit the response of astrocytes to $\mathrm{K}^{+}$stimulation; and (2) inhibition of glutamate release from neurons should block the $\left[\mathrm{Ca}^{2+}\right]_{\mathrm{i}}$ rise induced by high $\mathrm{K}^{+}$stimulation in astrocytes. The first of such predictions was verified in the experiment presented in Figure 3. Astrocytes were challenged with $60 \mathrm{mM} \mathrm{K}^{+}$after depleting their $\left[\mathrm{Ca}^{2+}\right]_{\mathrm{i}}$ stores with CPA, a potent and selective inhibitor of endoplasmic reticulum $\mathrm{Ca}^{2+}$ ATPase (Mason et al., 1991). As in the representative experiment reported in Figure 4, on slice perfusion with CPA $(50 \mu \mathrm{M})$, the great majority of astrocytes (14 of 15; three experiments), previously identified by their delayed response to a first challenge with $60 \mathrm{~mm} \mathrm{KCl}$, displayed a slow, progressive increase in their $\left[\mathrm{Ca}^{2+}\right]_{\mathrm{i}}$. Within 20-30 min from the onset of CPA application, a new steady state, slightly higher than the resting $\left[\mathrm{Ca}^{2+}\right]_{i}$, was reached. In these conditions, the stimulation with $t$-ACPD did not induce any significant $\left[\mathrm{Ca}^{2+}\right]_{\mathrm{i}}$ elevations (data not shown), although the second challenge with $\mathrm{K}^{+}$caused in 14 of 15 astrocytes a slow decrease in the $\left[\mathrm{Ca}^{2+}\right]_{i}$, as in the example reported in Figure 3, and no $\left[\mathrm{Ca}^{2+}\right]_{\mathrm{i}}$ change in the remaining one. The behavior of neurons was different. After CPA, their increase in $\left[\mathrm{Ca}^{2+}\right]_{i}$ was negligible, as in the case of Figure 3 . A clear $\left[\mathrm{Ca}^{2+}\right]_{i}$ increase during CPA application was observed in only 10\% (2 of 20) of the neurons analyzed. In contrast to the behavior of astrocytes, neurons responded to the two episodes of $\mathrm{K}^{+}$stimulation, the first in the absence and the second in the presence of CPA, with $\left[\mathrm{Ca}^{2+}\right]_{\mathrm{i}}$ increases of similar amplitude.

The second prediction was verified in the experiment presented in Figure 4. We reported previously that in slices incubated with TeNT $(100 \mu \mathrm{g} / \mathrm{ml})$, a highly specific blocker of neurotransmitter secretion in neurons (Calabresi et al., 1989; Schiavo et al., 1992), synaptic transmission was blocked, and stimulation of neuronal afferents failed to trigger any significant $\left[\mathrm{Ca}^{2+}\right]_{\mathrm{i}}$ increase in neurons as well as in astrocytes (Pasti et al., 1997). Preliminary observations also suggested that the $\left[\mathrm{Ca}^{2+}\right]_{\mathrm{i}}$ increase normally occurring in astrocytes on $\mathrm{K}^{+}$stimulation was grossly reduced by TeNT. Here we confirm and expand those initial observations. Figure $4 A$ shows the kinetics of $\left[\mathrm{Ca}^{2+}\right]_{\mathrm{i}}$ changes on high $\mathrm{K}^{+}$ stimulation in four representative cells, i.e., two neurons and two astrocytes, from a slice incubated for $40 \mathrm{~min}$ in $100 \mu \mathrm{g} / \mathrm{ml} \mathrm{TeNT}$. In these conditions, the response from these as well as the other astrocytes in six different experiments was virtually abolished (Fig. 4A,B). In two additional experiments, cells from TeNTtreated slices were followed for at least $10 \mathrm{~min}$, but any $\left[\mathrm{Ca}^{2+}\right]_{\mathrm{i}}$ increase was observed in astrocytes. In neurons the amplitude of the first $\left[\mathrm{Ca}^{2+}\right]_{\mathrm{i}}$ peak after a $\mathrm{KCl}$ challenge was unchanged by toxin treatment (Fig. 4B), although the second peak was either greatly reduced or absent (Fig. $4 A$ ). Figure $4 B$ reports the mean 

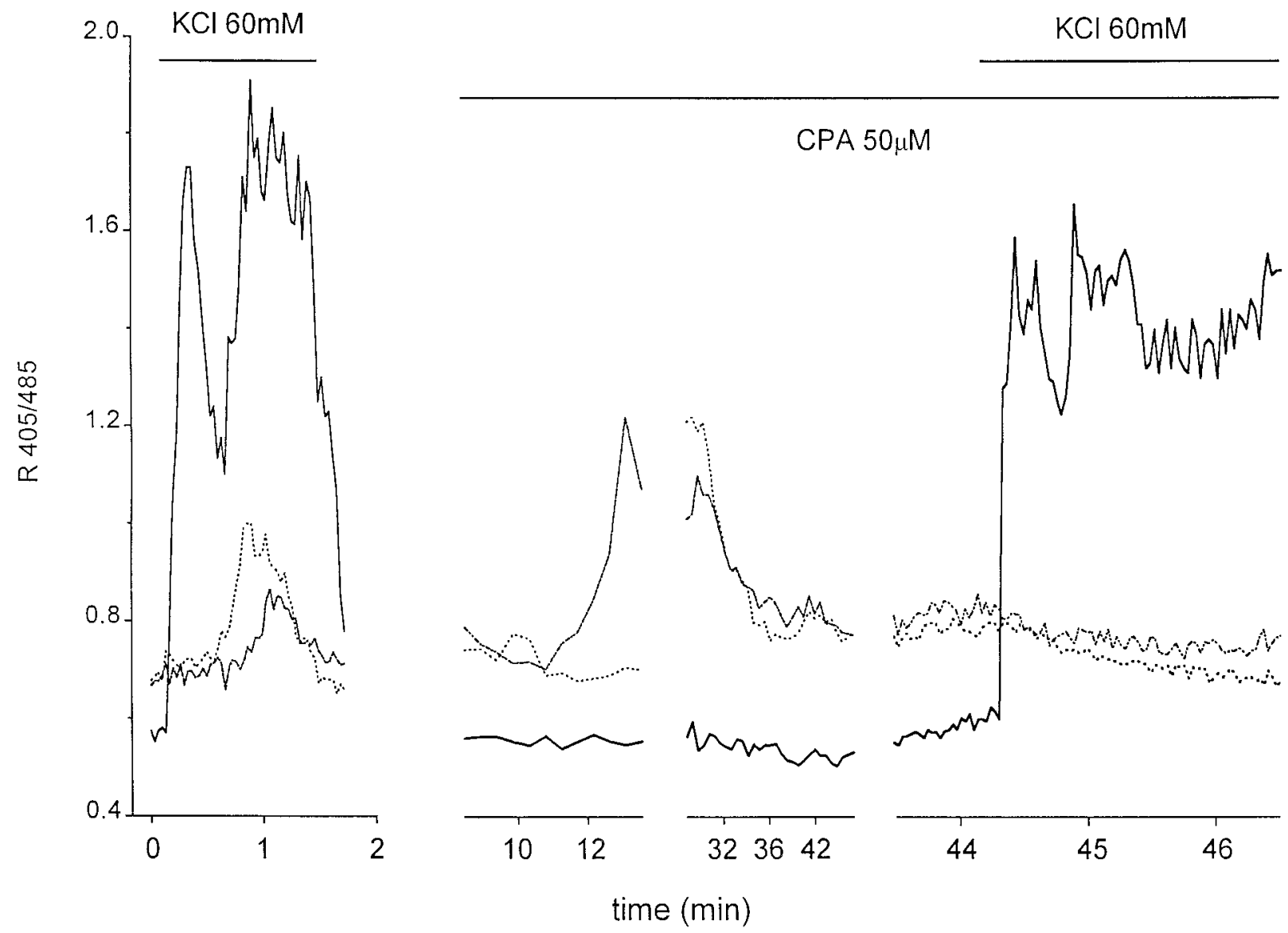

Figure 3. Kinetics of the $\left[\mathrm{Ca}^{2+}\right]_{\mathrm{i}}$ change in two astrocytes (dotted lines) and one pyramidal neuron (continuous lines) on $\mathrm{K}^{+}$stimulation before and 30 min after slice perfusion with CPA, an inhibitor of the endoplasmic reticulum ATPase. After the depletion of the $\left[\mathrm{Ca}^{2+}\right]_{\mathrm{i}}$ stores by CPA, the response of astrocytes to $\mathrm{K}^{+}$stimulation was abolished, whereas that of the neuron was unchanged. To reduced photobleaching, from the onset of CPA application until the second episode of $\mathrm{K}^{+}$stimulation, images were acquired every $30 \mathrm{sec}$.

A

$\mathrm{B}$

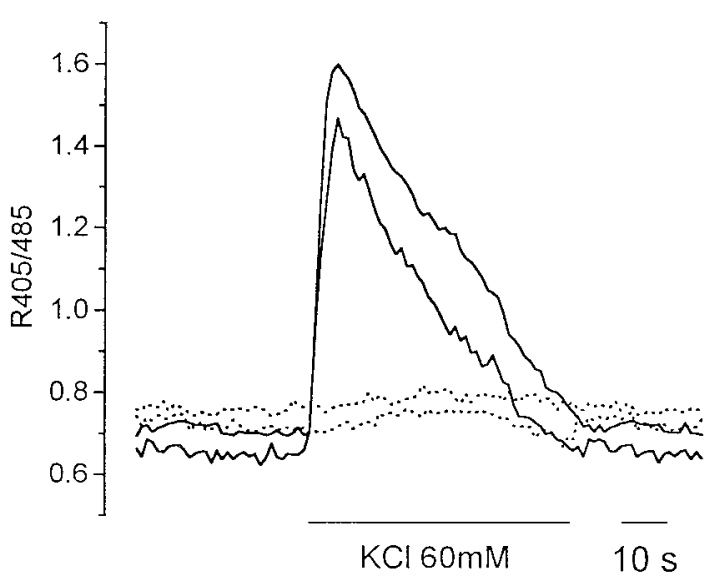

amplitude of the response of neurons (open bars) and astrocytes (stripped bars) to high $\mathrm{K}^{+}$stimulation in the absence and presence of TeNT. Noteworthy, TeNT has no specific effects on astrocyte $\mathrm{Ca}^{2+}$ handling. Indeed, after stimulation of the mGluR with $t$-ACPD $(10 \mu \mathrm{M})$, astrocytes from slices incubated with TeNT

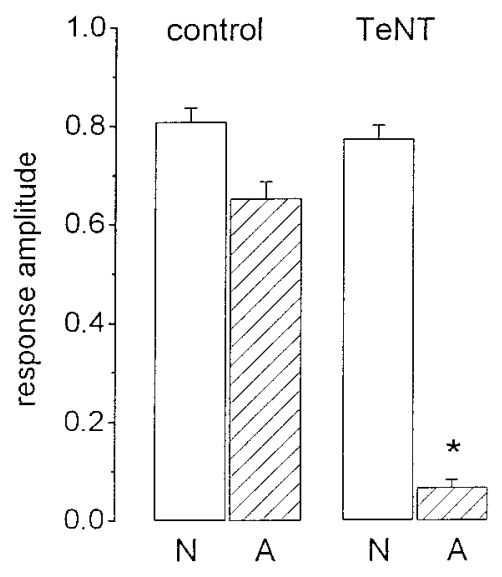

Figure 4. The response in neurons and astrocytes on $\mathrm{K}^{+}$stimulation is modified after TeNT treatment. $A$, Kinetics of the $\left[\mathrm{Ca}^{2+}\right]_{\mathrm{i}}$ changes in two representative neurons (continuous lines) and astrocytes (dotted lines) from the visual cortex of a 10 -d-old rat in response to stimulation with $60 \mathrm{mM} \mathrm{KCl}$ after slice incubation with TeNT. $B$, Mean values \pm SE of the change in R405:485 representing the amplitude of $\left[\mathrm{Ca}^{2+}\right]_{\mathrm{i}}$ elevations on $\mathrm{K}^{+}$stimulation in neurons $(N)$ and astrocytes $(A)$ from control slices (42 neurons and 27 astrocytes, 6 experiments) and TeNT-treated slices (63 neurons and 37 astrocytes, 6 experiments). ${ }^{*} p<0.001$. responded with a typical pattern of $\left[\mathrm{Ca}^{2+}\right]_{\mathrm{i}}$ changes, including $\left[\mathrm{Ca}^{2+}\right]_{\mathrm{i}}$ oscillations (data not shown).

Last but not least, if the preincubation with TeNT was reduced to $15-20 \mathrm{~min}$, instead of the usual 30-40 min, the stimulation with $60 \mathrm{~mm} \mathrm{KCl}$ induced a significant, although reduced, $\left[\mathrm{Ca}^{2+}\right]_{\mathrm{i}}$ 


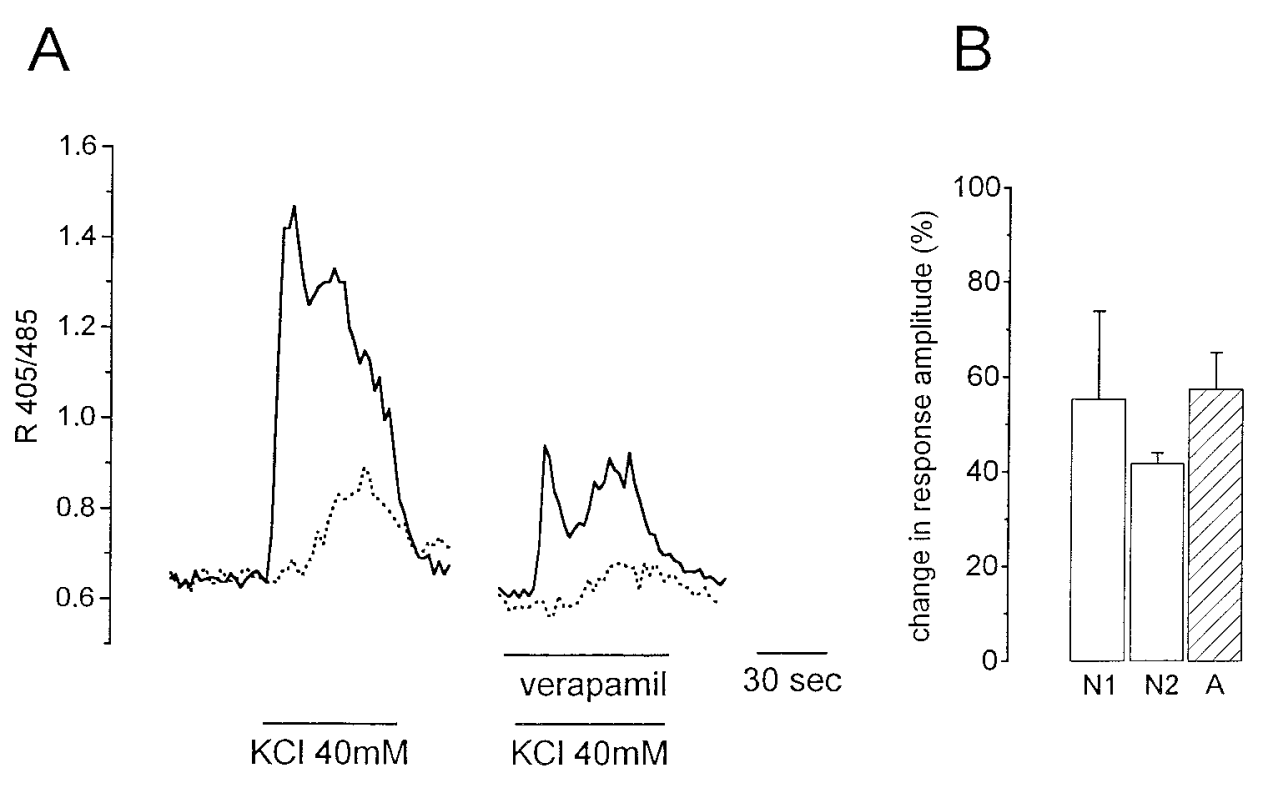

Figure 5. The $\mathrm{Ca}^{2+}$ channel blocker verapamil reduced the response of both neurons and astrocytes. $A$, Kinetics of the $\left[\mathrm{Ca}^{2+}\right]_{\mathrm{i}}$ change in one representative neuron (continuous line) and one astrocyte (dotted line) from the CA1 hippocampal region on $\mathrm{K}^{+}$ stimulation before and after slice perfusion with $100 \mu \mathrm{M}$ verapamil. $B$, Mean relative decrease $\pm \mathrm{SE}$ in the amplitude of the response to $\mathrm{K}^{+}$stimulation from neurons (open bars labeled $N 1$ and $N 2$ report the amplitude of the first and second $\left[\mathrm{Ca}^{2+}\right]_{\mathrm{i}}$ peaks respectively; $n=33,2$ experiments) and astrocytes ( $A$, stripped bars; $n=8,2$ experiments) after slice perfusion with 100 $\mu \mathrm{M}$ verapamil. increase in astrocytes ( $n=11$; two experiments). Under these conditions, the response was abolished in all astrocytes when $\mathrm{K}^{+}$ stimulation was performed in the presence of the mGluR antagonist MCPG (1 mM). On the contrary, MCPG did not affect the response in neurons.

In previous studies on acutely isolated astrocytes (Duffy and MacVicar, 1994) and astrocytes from acute brain slices (Porter and McCarthy, 1995; Duffy and MacVicar, 1996), it has been demonstrated that the $\mathrm{Ca}^{2+}$ VOC antagonist verapamil potently inhibits the $\left[\mathrm{Ca}^{2+}\right]_{\mathrm{i}}$ increase in astrocytes caused by high $\mathrm{K}^{+}$ stimulation. This observation was interpreted as an indication for the expression of $\mathrm{Ca}^{2+}$ VOCs in astrocytes in situ and for their crucial role in mediating the $\left[\mathrm{Ca}^{2+}\right]_{\mathrm{i}}$ increase in these cells on $\mathrm{K}^{+}$ stimulation. Here we have replicated that experiment and confirmed the observation. Verapamil was found to reduce by $\sim 50 \%$ the $\left[\mathrm{Ca}^{2+}\right]_{\mathrm{i}}$ increase induced in astrocytes by $40 \mathrm{mM} \mathrm{KCl}$, as in the typical example reported in Figure 5. However, under these conditions, the response from pyramidal neurons (both the first and second $\left[\mathrm{Ca}^{2+}\right]_{i}$ peaks) was also similarly inhibited (Fig. $5 A$ ). The mean reduction in the amplitude of the $\left[\mathrm{Ca}^{2+}\right]_{i}$ increase in neurons and astrocytes is reported in Figure $5 B$. Noteworthy, two subsequent applications of $40 \mathrm{~mm} \mathrm{KCl}$ performed in the absence of verapamil resulted in comparable responses from both astrocytes and neurons (data not shown). Taken together, the data of Figure 5 indicate that the inhibition by verapamil cannot be taken as evidence for the existence of $\mathrm{Ca}^{2+}$ VOCs in astrocytes, because its effect could be indirect and attributed to a partial inhibition of the glutamate release from neurons.

\section{Whole-cell patch clamping from astrocytes failed to reveal voltage-dependent $\mathrm{Ca}^{2+}$ currents}

The possible presence of voltage-dependent $\mathrm{Ca}^{2+}$ currents in astrocytes was finally investigated in acute hippocampal brain slices by using intracellular and extracellular solutions designed to reveal even small $\mathrm{Ca}^{2+}$ currents and to abolish $\mathrm{K}^{+}$and $\mathrm{Na}^{+}$ currents. After establishing the whole-cell configuration, depolarizing current pulses of increasing amplitude were applied to trigger action potential discharges that could reveal the possible neuronal identity of the patched cell. Immediately after this procedure, which did not take $>1 \mathrm{~min}$, the perfusion with the solution containing TEA and $10 \mathrm{mM} \mathrm{BaCl}_{2}$ was started, thus minimizing the time necessary for current analysis and limiting the rundown of the $\mathrm{Ca}^{2+}$ currents. The membrane was then hyperpolarized to $-110 \mathrm{mV}$ for $0.5 \mathrm{sec}$ from a holding potential of $-80 \mathrm{mV}$ and then depolarized to $+10 \mathrm{mV}$ for $100 \mathrm{msec}$ by a single step. Successive episodes were separated by $4 \mathrm{sec}$ intervals. After perfusion with the extracellular solution aimed to isolate $\mathrm{Ca}^{2+}$ currents, the $\mathrm{Na}^{+}$current, which was observed in 15 of a total of 18 recorded astrocytes, was rapidly reduced in amplitude and then blocked (Fig. 6A). No inward currents remained detectable under these conditions (Fig. 6B). As already reported in astrocytes acutely isolated from mouse hippocampus (Steinhäuser et al., 1994), the astrocyte $\mathrm{Na}^{+}$current was TTX-sensitive, as it rapidly disappeared after perfusion with $1 \mu \mathrm{M}$ TTX added to the standard extracellular solution $(n=3)$. After the disappearance of the $\mathrm{Na}^{+}$current, in nine astrocytes we compared the current traces before and after perfusion with $100 \mu \mathrm{M} \mathrm{Cd}^{2+}$, but no differences were detectable and, in no cases did the subtraction of the current traces disclose a $\mathrm{Cd}^{2+}$-sensitive inward current (Fig. 6C). In several experiments, LY was included in the patch pipette. All the astrocytes recorded $(n=8)$ were dye-coupled with at least two other astrocytes. Under the same experimental conditions, the $\mathrm{Na}^{+}$current recorded from a CA1 pyramidal neurons was progressively inhibited on slice perfusion with TEA and $\mathrm{BaCl}(10 \mathrm{~mm})$, and a distinct $\mathrm{Ca}^{2+}$ current appeared (Fig. $6 D)$. In a few experiments, by gentle withdrawing the patch pipette, we attained the detachment of the astrocyte cell body from the slice. Visual inspection revealed that some processes were relatively intact. Under these conditions, gap junction communication with other astrocytes was abolished, and the voltage control was presumably much better than in the astrocytes in situ. $\mathrm{No} \mathrm{Ca}^{2+}$ currents were, however, detected in three successfully detached astrocytes.

\section{DISCUSSION}

The main finding of this study is that the neuronal release of neurotransmitters is responsible for the $\left[\mathrm{Ca}^{2+}\right]_{\mathrm{i}}$ increase observed in astrocytes in situ on high $\mathrm{K}^{+}$stimulation. The contribution of $\mathrm{Ca}^{2+}$ VOCs in this event is, therefore, either absent or negligible. This conclusion derives from experiments performed in astrocytes from both rat visual cortex and CA1 hippocampal 


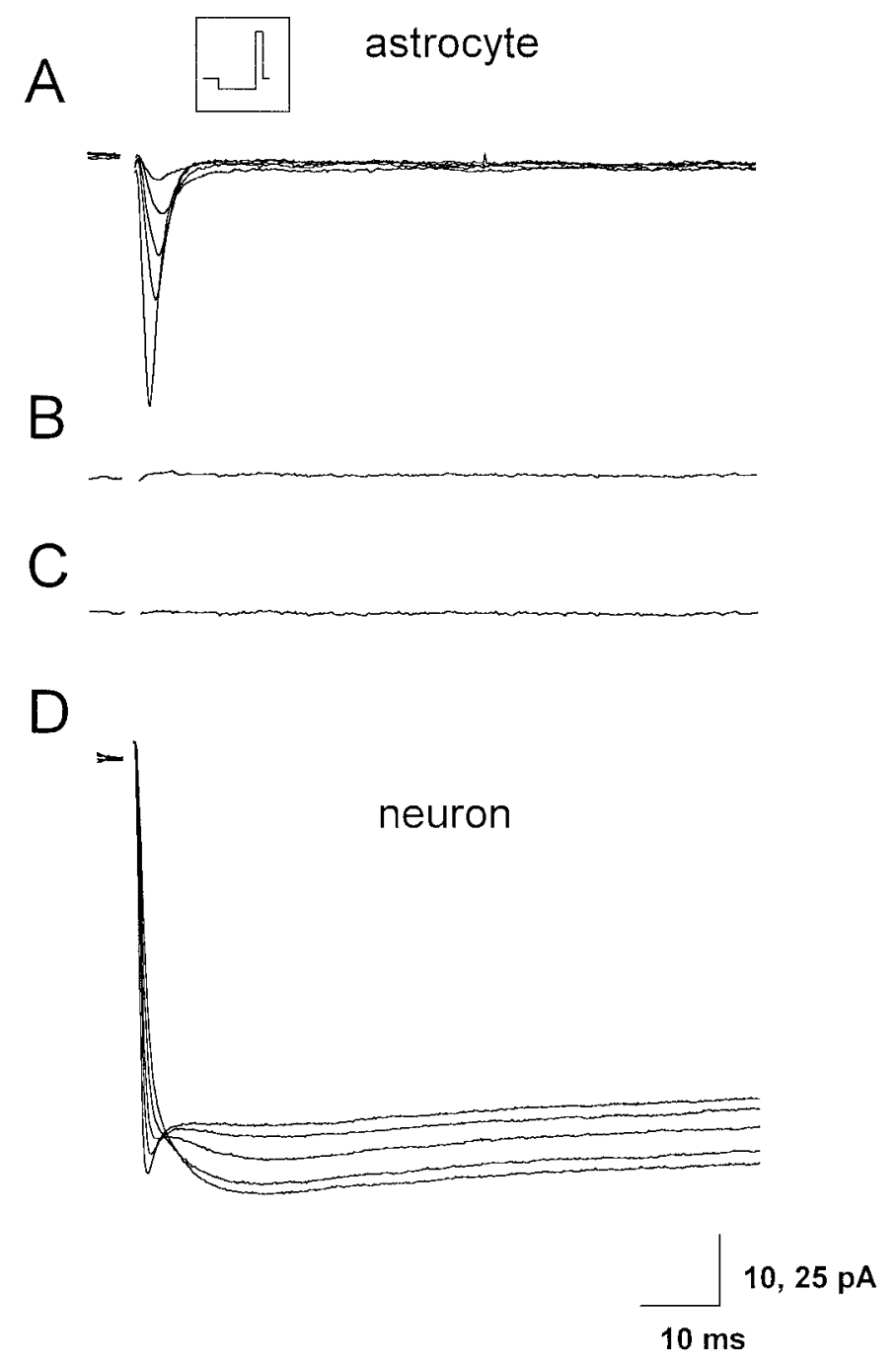

Figure 6. Whole-cell recordings of $\mathrm{Ba}^{2+}$ and $\mathrm{Na}^{+}$currents in hippocampal astrocytes and neurons. $A$, Progressive reduction of the $\mathrm{Na}^{+}$current recorded from one astrocyte from the CA1 hippocampal region of a 10-d-old rat on slice perfusion with $10 \mathrm{mM} \mathrm{BaCl}_{2}$ and TEA in substitution of $\mathrm{Na}^{+}$ions. The inset shows the pulse protocol used; the membrane was hyperpolarized to $-110 \mathrm{mV}$ from a holding potential of $-80 \mathrm{mV}$ for 0.5 sec and then depolarized to $0 \mathrm{mV}$ for $100 \mathrm{msec}$. Successive voltage pulses were separated by a $4 \mathrm{sec}$ interval. The capacitive transients have been blanked. LY included in the patch pipette diffused through gap junction from the recorded astrocyte into two other astrocytes (data not shown). $B$, No inward currents remain detectable after switching to $\mathrm{Na}^{+}$-free solution. $C$, Trace obtained after subtraction of the current traces recorded before and after $100 \mu \mathrm{M} \mathrm{Cd}^{2+}$ from the same astrocyte. $D$, Whole-cell recording from a CA1 pyramidal neuron of a 10-d-old rat with $\mathrm{Ba}^{2+}$ as charge carrier. Note the progressive increase of the $\mathrm{Ba}^{2+}$ current and the parallel reduction of the $\mathrm{Na}^{+}$current on slice perfusion (which started immediately after establishing the whole-cell configuration) with $10 \mathrm{~mm}$ $\mathrm{BaCl}_{2}$ and TEA in substitution of $\mathrm{Na}^{+}$ions. Stimulation protocol as in $A$.

region at P5-P18; therefore, it does not necessarily hold for astrocytes from other brain regions or at different developmental stages.

The remarkable delay occurring in astrocyte responses on a depolarizing stimulus with $40-60 \mathrm{~mm} \mathrm{KCl}$ with respect to the prompt $\left[\mathrm{Ca}^{2+}\right]_{\mathrm{i}}$ increase in neurons (Pasti et al., 1997) represents the initial observation that induced us to further investigate the role of $\mathrm{Ca}^{2+}$ VOCs in astrocytes. A plausible hypothesis that could account for the delayed $\left[\mathrm{Ca}^{2+}\right]_{\mathrm{i}}$ increase in astrocytes on high- $\mathrm{K}^{+}$-induced depolarization is that this response is caused by the action of neurotransmitters, such as glutamate and GABA, released by synaptic terminals. In other words, the $\left[\mathrm{Ca}^{2+}\right]_{\mathrm{i}}$ increase in astrocytes could represent a secondary response after activation by glutamate, and probably other neurotransmitters, of metabotropic receptors that trigger $\mathrm{IP}_{3}$-mediated release of $\mathrm{Ca}^{2+}$ from intracellular organelles. The significant reduction in the $\left[\mathrm{Ca}^{2+}\right]_{\mathrm{i}}$ increase in astrocytes induced by $\mathrm{K}^{+}$stimulation by $\mathrm{MCPG}$ is in agreement with the above-mentioned hypothesis. It should be noted that MCPG is a relatively weak competitive mGluR antagonist and could not completely prevent the action of glutamate massively released on the depolarizing stimulus. In addition, MCPG cannot block the action of other neurotransmitters, such as GABA, that can be released by neurons on depolarization and trigger $\left[\mathrm{Ca}^{2+}\right]_{\mathrm{i}}$ increase in astrocytes (Kettenmann et al., 1988; Nilsson et al., 1993).

The observation that the NMDAR antagonist D-AP-5 abolished the second $\left[\mathrm{Ca}^{2+}\right]_{i}$ peak observed in neurons on $\mathrm{K}^{+}$stimulation demonstrated that (1) significant amounts of glutamate are released on the depolarizing stimulus; and (2) $\mathrm{Ca}^{2+}$ entry through the NMDA receptor is responsible for the biphasic pattern of the neuronal response. Interestingly, in contrast to the lack of recovery observed in some neurons in the absence of D-AP-5, all neurons recovered $\left[\mathrm{Ca}^{2+}\right]_{\mathrm{i}}$ basal levels, and the time of recovery was also much faster in the presence of D-AP-5. These results confirm that neurons can hardly face $\mathrm{a}\left[\mathrm{Ca}^{2+}\right]_{\mathrm{i}}$ rise outside the physiological range when it derives from excessive stimulation of NMDA receptors.

Two pieces of experimental evidence conclusively demonstrate that the $\left[\mathrm{Ca}^{2+}\right]_{\mathrm{i}}$ increase occurring in astrocytes on a depolarizing stimulus is exclusively a glutamate-mediated response: (1) after emptying $\left[\mathrm{Ca}^{2+}\right]_{\mathrm{i}}$ stores with CPA, no astrocyte displayed a detectable $\left[\mathrm{Ca}^{2+}\right]_{i}$ increase on the depolarizing stimulus; and (2) no response to high $\mathrm{K}^{+}$stimulation was observed in astrocytes from slices incubated in TeNT. As to the first, after store depletion, opposite to expectation if $\mathrm{Ca}^{2+}$ VOCs were expressed in these cells, the depolarizing stimulus failed to cause any $\left[\mathrm{Ca}^{2+}\right]_{\mathrm{i}}$ increase in astrocytes but, rather, induced a progressive $\left[\mathrm{Ca}^{2+}\right]_{i}$ decrease. This latter observation is consistent with the expression in astrocytes of a $\mathrm{Ca}^{2+}$ release-activated $\mathrm{Ca}^{2+}$ influx (Hoth and Penner, 1992; Fasolato et al., 1994). Accordingly, the $\left[\mathrm{Ca}^{2+}\right]_{\mathrm{i}}$ decrease caused by depolarization likely depends on a decrease in the driving force for $\mathrm{Ca}^{2+}$ influx. As to the second, TeNT is known to be highly neuron-specific and to exert its action on VAMP/synaptobrevin, a protein that plays a crucial role in the neuroexocytosis process (Schiavo et al., 1992; Matteoli et al., 1996). The inhibitory effect of the neurotoxin on neurotransmitter exocytosis was confirmed in each slice by the observations that (1) electrical stimulation of Schaffer collaterals failed to induce $\left[\mathrm{Ca}^{2+}\right]_{\mathrm{i}}$ increases in hippocampal neurons otherwise observed in TeNT-untreated slices; (2) pyramidal neurons still responded to $\mathrm{K}^{+}$-induced depolarization with an early $\left[\mathrm{Ca}^{2+}\right]_{\mathrm{i}}$ increase, but the second $\left[\mathrm{Ca}^{2+}\right]_{\mathrm{i}}$ peak in their response was either greatly reduced or abolished; and (3) $\left[\mathrm{Ca}^{2+}\right]_{\mathrm{i}}$ basal levels were recovered much faster than in neurons from TeNT-untreated slices. The absence of $\left[\mathrm{Ca}^{2+}\right]_{\mathrm{i}}$ changes evoked in astrocytes from TeNTtreated slices conclusively confirms the hypothesis that glutamate released by depolarized synaptic terminals is responsible for the $\mathrm{K}^{+}$-induced $\left[\mathrm{Ca}^{2+}\right]_{\mathrm{i}}$ increase in astrocytes. The observation that astrocytes from TeNT-treated slices displayed typical $\left[\mathrm{Ca}^{2+}\right]_{\mathrm{i}}$ oscillations on slice perfusion with the mGluR agonist $t$-ACPD 
demonstrated that astrocytes can respond normally in the presence of TeNT.

Our conclusion is clearly in contrast with several studies supporting a role of $\mathrm{Ca}^{2+}$ VOCs in the $\mathrm{K}^{+}$-induced $\left[\mathrm{Ca}^{2+}\right]_{\mathrm{i}}$ increase in astrocytes in situ. In particular, in the presence of $\mathrm{Ca}^{2+}$ channel antagonists, the $\left[\mathrm{Ca}^{2+}\right]_{\mathrm{i}}$ increase on high $\mathrm{K}^{+}$depolarization in both acutely dissociated astrocytes (Duffy and MacVicar, 1994) and astrocytes from hippocampal slices was observed to be, at least partially, inhibited (Porter and McCarthy, 1995; Duffy and MacVicar, 1996). Although we obtained similar results, our interpretation is that $\mathrm{Ca}^{2+}$ VOC antagonists reduce the $\left[\mathrm{Ca}^{2+}\right]_{\mathrm{i}}$ increase in astrocytes on $\mathrm{K}^{+}$stimulation by blocking neuronal $\mathrm{Ca}^{2+}$ channels, thus causing a reduction in neurotransmitter release. The observation that verapamil also decreased the amplitude of the response from neurons supports our interpretation. In particular, given that the second $\left[\mathrm{Ca}^{2+}\right]_{i}$ peak in the neuronal response to $\mathrm{K}^{+}$stimulation is caused by the release of glutamate and to the consequent activation of the NMDA receptor, the finding that verapamil decreased the amplitude not only of the first but also of the second $\left[\mathrm{Ca}^{2+}\right]_{i}$ peak suggests that it directly affects the process of neurotransmitter release. Because the release of the neurotransmitter in the mammalian CNS is known to be controlled by various $\mathrm{Ca}^{2+}$ channels but not the L-type channel (Dunlap et al., 1995), verapamil most likely interferes, at least at the concentration used, not only with the L-type but also with other $\mathrm{Ca}^{2+}$ channels, such as the $\mathrm{N}$ - and P-type, that regulate exocytosis in hippocampal neurons.

The results we obtained are hardly compatible with the presence of functional VOCs in astrocytes in situ. Nevertheless, the possibility cannot be ruled out that astrocytes either express $\mathrm{Ca}^{2+}$ VOCs at very low density or express exclusively rapidly inactivating $\mathrm{T}$-type $\mathrm{Ca}^{2+}$ channels. In both cases, the $\left[\mathrm{Ca}^{2+}\right]_{\mathrm{i}}$ increase resulting from their activation might be too small or too rapid to be detectable, at least by our experimental approach with the confocal microscope.

Despite the various experimental conditions we used to detect even a small $\mathrm{Ca}^{2+}$ current, our patch-clamp study failed to reveal any $\mathrm{Ca}^{2+}$ currents from astrocytes in situ. Negative results were also obtained by recording from three astrocytes after their detachment from the slice. Under these conditions, gap junction communication with other astrocytes was most likely abolished, thereby allowing an adequate voltage control. Although unlikely, the possibility still remains that a low density of VOCs is expressed exclusively in the processes that were lost in the detached astrocytes.

We would like, however, to point out that even if $\mathrm{Ca}^{2+}$ VOCs are expressed in astrocytes, they do not contribute to the dramatic $\left[\mathrm{Ca}^{2+}\right]_{\mathrm{i}}$ change occurring in these cells on depolarization. This finding, therefore, has implications for the mechanism by which alterations in the extracellular $\mathrm{K}^{+}$possibly affect the function of astrocytes in vivo. In fact, it has been reported that pathological conditions such as ischemia or spreading depression lead to large elevations of extracellular $\mathrm{K}^{+}(60-80 \mathrm{~mm})$. These changes are accompanied by strong reductions in the concentration of extracellular $\mathrm{Ca}^{2+}$ (Nicholson et al., 1978). It has been suggested that the $\left[\mathrm{Ca}^{2+}\right]_{\mathrm{i}}$ increase observed in astrocytes under these conditions is the result of $\mathrm{Ca}^{2+}$ influx through $\mathrm{Ca}^{2+}$ VOCs. The hypothesis was then advanced that astrocytes can efficiently buffer $\mathrm{Ca}^{2+}$ in the extracellular space as much as they can buffer $\mathrm{K}^{+}$. By lowering $\mathrm{Ca}^{2+}$ in the synaptic cleft, astrocytes may reduce $\mathrm{Ca}^{2+}$ influx in neurons mediated by $\mathrm{Ca}^{2+}$ VOCs and ionotropic glutamate receptors, thus modifying $\mathrm{Ca}^{2+}$-dependent synaptic trans- mission and protecting neurons from cell death because of excessive elevations of $\left[\mathrm{Ca}^{2+}\right]_{\mathrm{i}}$ (Duffy and MacVicar, 1994). After the results reported here, the role of astrocyte $\mathrm{Ca}^{2+}$ VOCs in these processes should be reconsidered, at least at the developmental stages and in the brain regions investigated in this study. Noteworthy, we recently demonstrated that the activation of the mGluR in cultured astrocytes as well as in astrocytes from acute brain slices triggers, via prostaglandin formation, a significant $\mathrm{Ca}^{2+}$-dependent release of glutamate (Pasti et al., 1997; Bezzi et al., 1998). Through this glutamate-mediated glutamate release, astrocytes may thus contribute to, rather than protect from, the neuronal death that results from the excitoxic action of glutamate.

The possible contribution of $\mathrm{Ca}^{2+}$ VOCs in depolarizationdependent $\left[\mathrm{Ca}^{2+}\right]_{\mathrm{i}}$ changes in astrocytes under physiological conditions should also be reconsidered. A rise in the $\left[\mathrm{Ca}^{2+}\right]_{i}$ may modulate in astrocytes multiple events such as $\mathrm{Ca}^{2+}$-dependent $\mathrm{K}^{+}$channel activation (Quandt and MacVicar, 1986), nitric oxide production (Murphy et al., 1993), propagating $\left[\mathrm{Ca}^{2+}\right]_{\mathrm{i}}$ waves (Cornell-Bell et al., 1990; Finkbeiner, 1992) and, as already mentioned, the release of glutamate (Parpura et al., 1994; Jeftinija et al., 1996; Pasti et al., 1997; Bezzi et al., 1998). The source of $\mathrm{Ca}^{2+}$ that permits these changes can be either intracellular, i.e., release from stores, and/or extracellular, i.e., entry through plasma membrane channels and ion exchangers. Although a contribution of the $\mathrm{Na}^{+}$and $\mathrm{Ca}^{2+}$ exchanger cannot be excluded (Goldman et al., 1994), our results suggest that the release of $\mathrm{Ca}^{2+}$ from intracellular $\mathrm{Ca}^{2+}$ stores and the $\mathrm{Ca}^{2+}$ release-activated $\mathrm{Ca}^{2+}$ influx are major mechanisms used by astrocytes to achieve rises in their $\left[\mathrm{Ca}^{2+}\right]_{i}$ that could have functional significance for the triggering of $\mathrm{Ca}^{2+}$-dependent events.

\section{REFERENCES}

Akopian G, Kressin K, Derouiche A, Steinhäuser C (1996) Identified glial cells in the early postnatal mouse hippocampus display different types of calcium currents. Glia 17:181-194.

Barres BA, Chun LLY, Corey D (1989) Calcium current in cortical astrocytes: induction by cAMP and neurotransmitters and permissive effect of serum factors. J Neurosci 9:3169-3175.

Barres BA, Koroshetz WJ, Chun L, Corey D (1990) Ion channel expression by white matter glia: the type-1 astrocyte. Neuron 5:527-544.

Berridge MJ (1993) Inositol trisphosphate and calcium signaling. Nature 361:315-325.

Bezzi P, Carmignoto G, Pasti L, Vesce S, Rossi D, Lodi Rizzini B, Pozzan T, Volterra A (1998) Prostaglandins stimulate calciumdependent glutamate release in astrocytes. Nature 391:281-285.

Calabresi P, Benedetti M, Mercuri NB, Bernardi G (1989) Selective depression of synaptic transmission by tetanus toxin: a comparative study on hippocampal and neostriatal slices. Neuroscience 30:663-670.

Carmignoto G, Vicini S (1992) Activity-dependent decrease in NMDA receptor responses during development of the visual cortex. Science 258:1007-1011.

Charles AC, Merrill JE, Dirksen ER, Sanderson MJ (1991) Intracellular signaling in glial cells: calcium waves and oscillations in response to mechanical stimulation. Neuron 6:983-992.

Cornell-Bell AH, Finkbeiner SM, Cooper MS, Smith SJ (1990) Glutamate induces calcium waves in cultured astrocytes: long range glial signalling. Science 247:470-473.

Corvalan V, Cole R, De Vellis J, Hagiwara S (1990) Neuronal modulation of calcium channel activity in cultured rat astrocytes. Proc Natl Acad Sci USA 87:4345-4348.

Dunlap K, Luebke JI, Turner TJ (1995) Exocytotic $\mathrm{Ca}^{2+}$ channels in mammalian central neurons. Trends Neurosci 18:89-98.

Duffy S, MacVicar BA (1994) Potassium-dependent calcium influx in acutely isolated hippocampal astrocytes. Neuroscience 61:51-61.

Duffy S, MacVicar BA (1996) In vitro ischemia promotes calcium influx and intracellular calcium release in hippocampal astrocytes. J Neurosci $1: 71-81$. 
Edwards FA, Konnerth A, Sakmann B, Takahashi T (1989) A thin slice preparation for patch clamp recordings from synaptically connected neurones of the mammalian CNS. Pflügers Arch 414:600-612.

Fasolato C, Innocenti B, Pozzan T (1994) Receptor-activated Ca ${ }^{2+}$ influx: how many mechanisms for how many channels? Trends Pharmacol Sci 15:77-83.

Finkbeiner S (1992) Calcium waves in astrocytes: filling the gap. Neuron 8:1101-1108.

Glaum SR, Holzwarth JA, Miller RJ (1990) Glutamate receptors activate $\mathrm{Ca}^{2+}$ mobilization and $\mathrm{Ca}^{2+}$ influx into astrocytes. Proc Natl Acad Sci USA 86:3454-3458.

Goldman WF, Yarowsky PJ, Juhaszova M, Krueger BK, Blaustein MP (1994) Sodium/calcium exchange in rat cortical astrocytes. J Neurosci 14:5834-5843.

Hoth M, Penner R (1992) Depletion of intracellular stores activates a calcium current in mast cells. Nature 355:353-355.

Jabs R, Kirchoff F, Kettenmann H, Steinhäuser C (1994) Kainate activates $\mathrm{Ca}^{2+}$-permeable glutamate receptors and blocks voltage-gated $\mathrm{K}^{+}$currents in glial cells of mouse hippocampus. Pflügers Arch 426:310-319.

Jeftinija SD, Jeftinija FK, Stefanovic G, Liu F (1996) Neuroligandsevoked calcium dependent release of excitatory amino acids from cultured astrocytes. J Neurochem 66:676-684.

Jensen AM, Chiu SY (1991) Differential intracellular responses to glutamate in type 1 and type 2 cultured brain astrocytes. J Neurosci 11:1674-1684.

Kettenmann H, Backus KH, Schachner M (1988) GABA receptor on cultured astrocytes. In: Glial cell receptors (Kimelberg HK, ed), pp 95-106. New York: Raven.

Kressin K, Kuprijanova E, Jabs R, Seifert G, Steinhäuser C (1995) Developmental regulation of $\mathrm{Na}^{+}$and $\mathrm{K}^{+}$conductances in glial cells of mouse hippocampal brain slices. Glia 15:173-187.

MacVicar BA (1984) Voltage-dependent calcium channels in glial cells. Science 226:1345-1347.

MacVicar BA, Tse FWY (1988) Norepinephrine and cyclic adenosine $3^{\prime}: 5^{\prime}$-cyclic monophosphate enhance a nifedipine-sensitive calcium current in cultured astrocytes. Glia 1:359-365.

MacVicar BA, Hochman D, Dealy MJ, Weiss S (1991) Modulation of intracellular $\mathrm{Ca}^{2+}$ in cultured astrocytes by influx through voltageactivated $\mathrm{Ca}^{2+}$ channels. Glia 4:448-455.

McKhann II GM, D’Ambrosio R, Janigro D (1997) Heterogeneity of astrocyte resting membrane potential and intercellular coupling revealed by whole-cell and gramicidin-perforated patch recording from cultured astrocytes. J Neurosci 17:6850-6863.

Mason MJ, Garcia-Rodriguez C, Grinstein S (1991) Coupling between intracellular stores and permeability of the plasma membrane: comparison of the effects of thapsigargin, 2,5-Di-(ter-butyl)-1,4-hydroquinone, and cyclopiazonic acid in rat thymic lymphocytes. J Biol Chem 266:20856-20862.

Matteoli M, Verderio C, Rossetto O, Iezzi N, Cocco S, Schiavo G, Montecucco C (1996) Synaptic vesicle endocytosis mediates the entry of tetanus toxin into hippocampal neurons. Proc Natl Acad Sci USA 93:13310-13315.

Murphy S, Simmonds ML, Agullo L, Garcia A, Feinstein DL, Galea E, Reis DJ, Minc-Golomb D, Schwartz JP (1993) Synthesis of nitric oxide in CNS glial cells. Trends Neurosci 16:323-328.

Nicholson C, Bruggencate GT, Stockle H, Steinberg R (1978) Calcium and potassium changes in extracellular microenvironment of cat cerebellar cortex. J Neurophysiol 41:1026-1039.

Nilsson M, Eriksson PS, Ronback L, Hansson E (1993) GABA induces transients on astrocytes. Neuroscience 54:605-614.

Palmer E, Monaghan DT, Cotman CW (1989) Trans-ACPD, a selective agonist of the phosphoinositide-coupled excitatory amino acid receptor. Eur J Pharmacol 166:585-587.

Parpura V, Basarky TA, Liu F, Jeftinija FK, Jeftinija SD, Haydon PG (1994) Glutamate-mediated astrocyte-neuron signalling. Nature 369:744-747.

Pasti L, Pozzan T, Carmignoto G (1995) Long-lasting changes of calcium oscillations in astrocytes. A new form of glutamate-mediated plasticity. J Biol Chem 25:15203-15210.

Pasti L, Volterra A, Pozzan T, Carmignoto G (1997) $\left[\mathrm{Ca}^{2+}\right]_{\mathrm{i}}$ oscillations in astrocytes triggers repetitive glutamate-mediated $\left[\mathrm{Ca}^{2+}\right]_{\mathrm{i}}$ increases in neurons in situ. J Neurosci 17:7817-7830.

Porter JA, McCarthy KD (1995) GFAP-positive hippocampal astrocytes in situ respond to glutamatergic neuroligand with increased in $\left[\mathrm{Ca}^{2+}\right]_{\mathrm{i}}$. Glia 13:101-112.

Quandt FN, MacVicar BA (1986) Calcium activated potassium channels in cultured astrocytes. Neuroscience 19:29-41.

Rice ME, Pérez-Pinzón MA, Lee EJK (1994) Ascorbic acid, but not glutathione, is taken up by brain slices and preserves cell morphology. J Neurophysiol 71:1591-1560.

Scheenen WJJM, Makings LR, Gross LR, Pozzan T, Tsien RY (1996) Photodegradation of Indo- 1 and its effects on apparent $\mathrm{Ca}^{2+}$ concentration. Chem Biol 3:765-774.

Schiavo G, Montecucco C (1995) Tetanus and botulinum neurotoxins: isolation and assay. Methods Enzymol 248:643-652.

Schiavo G, Benfenati F, Puolain B, Rossetto O, Polverino de Laureto P, DasGupta BR, Montecucco C (1992) Tetanus and botulinum-B neurotoxins block neurotransmitter release by proteolitic cleavage of synaptobrevin. Nature 359:832-835.

Steinhäuser C, Kressin K, Kuprijanova E, Weber M, Seifert G (1994) Properties of voltage-activated sodium and potassium currents in mouse hippocampal glial cells in situ and after acute isolation from tissue slices. Pflügers Arch 428:610-620.

Verkhratsky A, Kettenmann H (1996) Calcium signaling in glial cells. Trends Neurosci 19:346-352.

Watkins JC, Collingridge GL (1994) Phenylglycine derivatives as antagonists of metabotropic glutamate receptors. Trends Pharmacol Sci 15:333-342.

Watkins JC, Krogsgaard-Larsen P, Honoré T (1990) Structure-activity relationships in the development of excitatory amino acid receptor agonists and competitive antagonists. Trends Pharmacol Sci 11:25-33. 